\title{
Interactive comment on "Sources of nitrous acid (HONO) in the upper boundary layer and lower free troposphere of North China Plain: insights from the Mount Tai Observatory" by Ying Jiang et al.
}

\section{Anonymous Referee \#2}

Received and published: 10 July 2020

This manuscript describes measurements of Nitrous Acid (HONO) and a suite of other trace gases at a mountaintop site (Mt. Tam Observatory) on the North China Plain. Their goal was to assess whether currently understood HONO sources could explain measured HONO mixing ratios at the (sometimes), free tropospheric site. The authors use their observations coupled with model output to calculate midday HONO photostationary state values (PSS) and compare their observations with Master Chemical Mechanism (MCM) model output. Closing the HONO budget has been a challenging long-standing issue within the community and this paper is a further attempt to do so. The publication is generally well written and the content falls within the scope of Atmospheric Chemistry and Physics. I recommend publication once the following comments 
are addressed.

Major Comments:

While the Long Path Absorption Photometer Technique (LOPAP) has been extensively tested for a variety of interferences (Heland et al., 2001;Kleffmann and Wiesen, 2008), it has been shown to have an interference from peroxynitric acid (HO2NO2, PNA), (Legrand et al., 2014). While in many studies ambient temperatures would have rendered this potential interference negligible, I cannot help but feel this is the type of scenario where it could potentially be a problem. The temperatures under which these measurements were performed (and NOx levels) should support a long enough PNA lifetime for it to be observed. In addition, the authors indicate that the missing HONO source should scale with solar radiation and NO2. PNA should also scale with both of these parameters. While it would be nice to have a full interference test of the instrument for PNA, synthesizing or developing photolytic generation sources can be a challenge. The authors should address this by adding a section discussing the possibility of the interference. Using their MCM model runs they could provide an estimate of what best/worst case scenarios would look like. I doubt that PNA alone is the missing "HONO" source, however constraining the possibility of interference could give a more accurate picture to how much $\mathrm{HONO}$ is in fact missing.

\section{Specific Comments:}

Please indicate where the data and model output are available to readers. Title: Should be "The North China Plain"? P1 L20: Are the mixing ratios means or medians? What are they? I believe it is mentioned further in the text, but it should be noted here as well. P1 L21: Could the noontime max be biased by measuring HO2NO2 (see major comments)? P1 L27: Would a source consistent with NO2 not also be consistent with HO2NO2 (see major comments)? P4 L9: Change the wording of "Observatory has been widely deployed". You don't really deploy a building. Perhaps "Observatory has been widely used as a sampling location" ? P6 L22: What do the authors mean by 
approximated by the $\mathrm{CO}$ (Temperature) data? Was it approximated by $\mathrm{CO}$ or temperature? Please clarify. P7 L27: I find the description of AOC to be confusing. Are the authors simply trying to describe $\mathrm{OH}$-Reactivity or something else? Please clarify. P7 L8: This wording is a bit ackward "The atmospheric conditions at Mt. Tai were featured by a cold and dry weather". Perhaps "The atmospheric conditions at Mt. Tai were dominated by cold and dry weather."? P9 L18: "It can be argued that the heterogeneous formation of HONO should be stronger at the mountaintop, which may be due to the more intense solar radiation at the high altitudes." Why can this be argued? The ratios are almost within one standard deviation of each other. This would potentially be true assuming the source scales with light intensity, but what would the difference in surface area for the heterogeneous reaction be? That's not clear.

P9 L31: Is there no newer reference than 1973? Surely there have been some advances.

P10 L6: The surface HONO would most certainly be extensively diluted by the time it reached the elevated site. Could the authors not use a conserved tracer to estimate the dilution? Or for that matter the upslope time?

P13 L20: How do you know the model underestimated the HOx radical levels? I am unaware of $\mathrm{HOx}$ measurements as part of this campaign constraining this. They aren't noted anywhere. This (as well as in the conclusion) should be re-worded.

Figure 2: While the shaded areas currently represent standard error of the measurement, perhaps showing standard deviation of the measurement might be more useful so that the reader can get a better feel for the range of values observed.

Figure 5: A figure showing the relative contribution of each of known HONO formation pathways would also be nice so that readers can get a visual idea of the importance of each pathway at this location.

Printer-friendly version

References: 
Heland, J., Kleffmann, J., Kurtenbach, R., and Wiesen, P.: A New Instrument To Measure Gaseous Nitrous Acid (HONO) in the Atmosphere, Environmental Science \& Technology, 35, 3207-3212, 2001.

Kleffmann, J., and Wiesen, P.: Technical Note: Quantification of interferences of wet chemical HONO LOPAP measurements under simulated polar conditions, Atmos.Chem.Phys., 8, 6813-6822, 2008.

Legrand, M., Preunkert, S., Frey, M., Bartels-Rausch, T., Kukui, A., King, M. D., Savarino, J., Kerbrat, M., and Jourdain, B.: Large mixing ratios of atmospheric nitrous acid (HONO) at Concordia (East Antarctic Plateau) in summer: a strong source from surface snow?, Atmos. Chem. Phys., 14, 9963-9976, 10.5194/acp-14-9963-2014, 2014.

Interactive comment on Atmos. Chem. Phys. Discuss., https://doi.org/10.5194/acp-2020-377, 2020. 